\title{
THE INFLUENCE OF POLICY ON REGULATED PREPAID CARD PERFORMANCE IN SOUTH AFRICA
}

\author{
Vanitha Padayachee, Da Vince Institute of Technology, South Africa \\ Richard Chinomona, University of the Witwatersrand, South Africa
}

dx.doi.org/10.18374/IJBR-17-3.6

\begin{abstract}
Although South Africa has a sophisticated financial sector characterised by well-developed infrastructure and technology, the economy remains primarily cash-based owing to the large informal sector. While inclusion in the mainstream financial marketplace has long been on the minds of policymakers, the policy guidelines of the prepaid card that could be adopted to accelerate financial inclusion is vague. For the banking sector, it is imperative that there is understanding of what are the implications of a deficient policy, so that it can be remedied, as this has a benefit that is two-fold: Increasing financial inclusion and at the same time creating business value. Consequently, the study investigates the influence of deficient policy guidelines on insufficient customer education, risk-based issuance by banks, inadequate customer education and sluggish product performance. This study uses a survey questionnaire for primary data collection and the gathered data is used to test the hypotheses quantitatively. Through SmartPLS statistical software - and by means of Structural Equation Modeling (SEM) - the significance of the variables in this study is determined from a sample of 140 respondents who were employed by businesses issuing prepaid cards across South Africa. The findings reveal that four of the hypotheses are supported and two are rejected. In addition, the findings reveal that deficient policy guidelines are the key antecedents for consumer take-up intentions in terms of prepaid cards with it having the greatest impact on customer support initiatives. The research study has implications for both policy makers and the banking sector.
\end{abstract}

Keywords: Deficient policy guidelines; insufficient customer education; Sluggish product performance; inadequate customer support; Risk issuance banks. 